\author{
Сравнение вариантов построения \\ абонентской аппаратуры ретрансляции \\ телеметрической информации РН, РБ и КА \\ через спутник-ретранслятор системы «Луч» \\ С. И. Ватутин \\ к. т.н., ОАО «Российские космические системь» \\ e-mail:otd0943_vsi@mail.ru
}

\begin{abstract}
Аннотация. Проведено сравнение вариантов построения абонентской аппаратуры ретрансляции на основе многоканальных радиолиний и на базе одноканальной радиолинии с фазированной антенной решеткой. Предложено трехступенчатое построение абонентской аппаратуры ретрансляции на основе трехканальной радиолинии.
\end{abstract}

Ключевые слова: энергетический потенциал радиолинии, антенна, коэффициент усиления антенны, скорость передачи информации, активная фазированная антенная решетка

\title{
Comparison of Construction Variants of Retransmitting Equipment of TM-Information from Carrier Rockets, Upper-Stage Rockets and Space Vehicles Via "Luch" Satellite Re-Transmitter
}

\author{
S. I. Vatutin \\ candidate of engineering science, Joint Stock Company "Russian Space Systems" \\ e-mail:otd0943_vsi@mail.ru
}

\begin{abstract}
It is done comparison of construction variant of subscriber retransmitting equipment on multi-channel radio link base as compared with variant on single-channel radio link with phased-array antenna base. It is proposed three-stage construction variant of subscriber retransmitting equipment on three-channel radio link base.
\end{abstract}

Key words: radio link power budget, antenna, antenna gain, information rate, phased-array antenna 
При запуске космического аппарата (KA) с космодрома Байконур на геостационарные орбиты и орбиты ГЛОНАСС импульсы разгона для выхода с опорной на переходную орбиту, как правило, осуществляются разгонными блоками вне зоны радиовидимости с территории России примерно над Южной Америкой. При этом, в силу отсутствия в настоящее время системы ретрансляции телеметрии на территорию России с обратной стороны Земли, контроль проведенных импульсов разгона разгонного блока (РБ) осуществляется путем нацеливания антенн телеметрических средств на «штатную» и «аварийную» орбиту, соответственно, для запланированной величины разгонного импульса двигателей РБ и полного отсутствия такового. Всевозможные промежуточные аварийные значения импульса разгона во внимание не принимаются из-за отсутствия в наземном автоматизированном комплексе управления (НАКУ) КА достаточного количества станций слежения. Ситуация существенно усложняется в связи с появлением в настоящее время «интеллектуальных» РБ типа «Волга», которые могут самостоятельно принимать решение о требуемой величине разгонного импульса в зависимости от фактических параметров опорной орбиты, что может привести к нескольким возможным реализациям переходной орбиты и, соответственно, к нескольким возможным точкам входа в зону радиовидимости телеметрических средств НАКУ. Отсюда настоятельная необходимость знать вектор состояния РБ $\left(X, Y, Z, V_{X}, V_{Y}, V_{Z}\right)$ на момент окончания импульса разгона. Та же самая проблема существует относительно КА при отделении его от ракеты-носителя (PH) на обратной стороне Земли: для телеметрического контроля на территории России надо знать векторы состояния $\mathrm{PH}$ и KA на момент их разделения. Таким образом, минимально необходимый объем информации, который надо передать с РН, КА и РБ через спутник-ретранслятор (СР) для их своевременной и надлежащей встречи по нужному направлению средствами НАКУ, состоит в передаче вектора состояния из 6 параметров плюс время окончания импульса. Пусть для передачи координаты, скорости или времени достаточно 4 байтов. Тогда минимально необходимый объем информации для встречи KA и РН составляет всего 28 байтов или 224 бита, что с учетом накладных расходов приведет к объему порядка 1 Кбит. То есть по радиолинии со скоростью порядка 1 кбит/с минимально необходимый объем информации для «встречи» объекта ракетнокосмической техники (ОРКТ - РН, РБ или КА) после импульса разгона, отделения или совершения маневра может быть передан не более чем за $1-2$ c.

Теперь перейдем к оценке скорости передачи информации через спутник-ретранслятор, которую может обеспечить одна антенна абонентской аппаратуры ретрансляции (ААР) с опорной орбиты.

Энергетический потенциал радиолинии ОРКТ-СР определяется классической формулой $[1,2]$ :

$$
P_{r}=\frac{P_{t} \cdot G_{t} \cdot \eta_{\text {п }} \cdot S_{\ni ф r}}{4 \cdot \pi \cdot r^{2}},
$$

где:

$P_{r}-$ мощность сигнала на входе приемника, Вт; $\eta_{\text {п }}=\eta_{t} \cdot \eta_{r} \cdot \eta_{\text {пол }} \cdot \eta_{\text {н }}-$ результирующий коэффициент потерь при передаче сигнала в тракте OPKT-CP;

$P_{t}-$ мощность передатчика;

$G_{t}-$ коэффициент усиления антенны передатчика;

$\eta_{t}-$ коэффициент полезного действия АФУ передатчика;

$\eta_{r}-$ коэффициент полезного действия АФУ приемника;

$\eta_{\text {пол }}-$ коэффициент поляризационных потерь;

$\eta_{\text {н }}-$ коэффициент потерь от неточного наведения антенн;

$S_{\text {эфr }}-$ эффективная поверхность приемной антенны;

$r$ - наклонная дальность.

С другой стороны, справедливо выражение [1]:

$$
P_{r}=\left(\frac{P_{r}}{P_{\text {ш }}}\right)_{\text {треб́ }} \cdot 2 \cdot k_{0} \cdot m \cdot t^{\circ} \cdot R,
$$

где $k_{0}=1,38 \cdot 10^{-23}-$ постоянная Больцмана;

$t^{\circ}$ - эквивалентная шумовая температура входного каскада приемника;

$R$ - скорость передачи информации;

$m-$ коэффициент, учитывающий количество лепестков спектра радиосигнала, попадающих в полосу приемника, обычно $m=1,2$, максимум 3 . 
Из (1) и (2) получаем:

$$
R=\frac{G_{t} \cdot K_{t} \cdot \eta_{\text {п }} \cdot S_{\text {эф } r}}{4 \cdot \pi \cdot r^{2} \cdot\left(\frac{P_{r}}{P_{\text {ш }}}\right)_{\text {треб }} \cdot 2 \cdot k_{0} \cdot m \cdot t^{\circ}} .
$$

Коэффициент усиления апертурной антенны определяется известным выражением:

$$
G=\frac{4 \cdot \pi \cdot S_{\ni \phi}}{\lambda^{2}}=\frac{4 \cdot \pi \cdot S_{\ni \phi}}{\left(\frac{c}{f_{\mathrm{H}}}\right)^{2}},
$$

где $\lambda$ и $f_{\text {н }}$ - длина волны и значение несущей частоты, $c-$ скорость света в свободном пространстве. Из (3) с учетом (4) получаем следующее выражение для оценки достижимой скорости передачи информации по исходным данным из [3] для радиолинии ОРКТ-СР:

$$
R=\frac{P_{t} \cdot G_{t} \cdot \eta_{\text {п }} \cdot\left(\frac{c}{f_{\mathrm{H}}}\right)^{2} \cdot G_{r}}{(4 \cdot \pi \cdot r)^{2} \cdot\left(\frac{P_{r}}{P_{\text {ш }}}\right)_{\text {треб }} \cdot 2 \cdot k_{0} \cdot m \cdot t^{\circ}} .
$$

Опираясь на исходные данные разработчиков AAP [3], приняв коэффициент усиления микрополосковой антенны ААР равномерным в полусфере и равным 2 , а также считая, что при фазовой манипуляции на $\pm 180^{\circ}$ с запасом достаточна полоса частот с 2 лепестками спектра радиосигнала, получены следующие опорные значения допустимых скоростей передачи информации в одном канале с одной антенны ОРКТ:

- для широкого луча СР в режиме многостанционного доступа (МСД): 97 бит/с;

- для узкого луча СР в режиме индивидуального доступа (ИД): 9260 бит/с.

Таким образом, из линейки типовых скоростей передачи ТМИ в 1, 8, 32, 64, 128, 256, 512 кбит/с, $1,2,3$ Мбит/с одна антенна на ОРКТ при отсутствии помехоустойчивого кодирования радиосигнала обеспечивает только две низшие скорости в 1 и 8 кбит/с и только при работе по узкому лучу.

В работе [4] показано, что из кодов с исправлением ошибок наибольший энергетический выигрыш в 8,9 дБ или в 7,76 раза дают так называемые турбокоды. С учетом кодирования турбокодом получаем следующие допустимые скорости передачи информации с одной антенны OPKT:

- для широкого луча СР в режиме МСД: $97 \times$ $\times 7,76=752$ бит $/$;

- для узкого луча СР в режиме ИД: 9260 $7,76=$ $=71857$ бит $/ \mathrm{c}$.

Таким образом, при помехоустойчивом кодировании одноканальная система передачи информации через одну антенну ОРКТ может обеспечить 4 низшие скорости передачи информации в $1,8,32$ и 64 кбит/с по узкому лучу СР.

Широкий луч может использоваться только для передачи малых объемов наиболее существенной информации типа навигационного вектора состояния ОРКТ. Но поскольку экспертные оценки показывают, что успешными были только $75 \%$ попыток наведения узкого луча спутникаретранслятора на космическую станцию «Мир» для первой реализации системы «Луч» на базе KA «Альтаир», то возможностью работы по широкому лучу пренебрегать нельзя.

Поэтому система передачи информации с ОРКТ через СР должна содержать две компоненты: низкоскоростную систему передачи по широкому лучу телесигнализации о навигационном векторе состояния ОРКТ после маневра и систему передачи ТМИ по узкому лучу.

Для реализации передачи ТМИ по узкому лучу со скоростями 128, 256, 512 кбит/с, 1, 2, 3 Мбит/с потребуется соответствующим образом увеличить энергетический потенциал радиолинии OPKT-CP, установив на OPKT, соответственно, $2,4,8,15,29,43$ антенны и передатчика. При этом, естественно, не возбраняется передавать информацию через несколько антенн и по широкому лучу спутника-ретранслятора. Данные о возможных скоростях передачи информации в многоантенной ААР через одноканальную радиолинию с активной фазированной антенной решеткой (АФАР) и через многоканальную радиолинию (МКРЛ) сведены в таблицу.

Далее можно поступить двояко:

1) объединить все $N$ всенаправленных в полусфере антенн в антенную решетку и направить ее 
Таблица. Допустимые скорости передачи информации в многантенной ААР с помехоустойчивым кодированием турбокодом

\begin{tabular}{|l|c|c|c|c|c|c|c|c|}
\hline Количество антенн в ААР & 1 & 2 & 4 & 8 & 15 & 29 & 43 \\
\hline \multicolumn{7}{|c|}{ Индивидуальный доступ } \\
\hline Скорость передачи информации, кбит/с & 64 & 128 & 256 & 512 & 1024 & 2048 & 3072 \\
\hline Мощность на передачу АФАР & 20 & 20 & 20 & 20 & 20 & 20 & 20 \\
\hline Мощность на передачу МКРЛ & 20 & 40 & 80 & 160 & 300 & 580 & 860 \\
\hline \multicolumn{7}{|c|}{ Многостанционный доступ } \\
\hline Скорость передачи информации, кбит/с & 0,7 & 1,4 & 2,9 & 5,8 & 11 & 21 & 31 \\
\hline Мощность на передачу АФАР & 20 & 20 & 20 & 20 & 20 & 20 & 20 \\
\hline Мощность на передачу МКРЛ & 20 & 40 & 80 & 160 & 300 & 580 & 860 \\
\hline
\end{tabular}

на СР. Тогда суммарная эффективная площадь антенн будет равна $N \cdot S_{э ф t}$, где $S_{\text {эфt }}-$ эффективная площадь одной передающей антенны ОРКТ, и в соответствии с (4) коэффициент усиления антенной решетки из $N$ антенн будет равен $G_{N t}=N \cdot G_{t}$, а в соответствии с (5) скорость передачи информации может быть увеличена в $N$ раз;

2 ) использовать $N$-канальную систему передачи на $N$ несущих частотах через те же $N$ передатчиков и $N$ антенн, что приведет к тому же увеличению суммарной скорости передачи информации в $N$ раз, не потребует дополнительных средств наведения антенной решетки ОРКТ на СР, но в $N$ раз увеличит потребляемую мощность, что очень критично для бортовых систем, особенно для КА и РБ.

Очевидно, второй способ гораздо проще и надежнее, но требует большего энергопотребления кратно количеству используемых антенн.

Основной недостаток применения направленной антенной решетки для передачи телеметрии с OPKT состоит в том, что предполагает безотказность систем ориентации, стабилизации и управления абонентских РН/РБ/КА, иначе радиолиния $\mathrm{PH} / \mathrm{PБ} / \mathrm{KA}-\mathrm{CP}$ работать не будет. Жесткое требование работоспособности основных бортовых систем справедливо при передаче целевой информации КА, но недопустимо при передаче с $\mathrm{PH} / \mathrm{PБ} / \mathrm{KA}$ телеметрической информации, которая является основой при идентификации неисправностей на борту $\mathrm{PH} / \mathrm{PБ/КА.} \mathrm{Отказы} \mathrm{или} \mathrm{нарушения} \mathrm{в} \mathrm{ра-}$ боте систем управления, ориентации и/или стабилизации $\mathrm{PH} / \mathrm{PБ} / \mathrm{KA}$ отнюдь не редкое явление. Именно поэтому одно из основных требований к телеметрической радиолинии - способность ра- ботать на ненаправленную антенну РН/РБ/КА. Однако многоканальная система имеет повышенное энергопотребление, что особенно критично для КА и РБ. Исходя из данных таблицы многоканальную ААР нецелесообразно применять при скоростях передачи данных свыше 256 кбит/с при работе с каналом индивидуального доступа спутникаретранслятора и при скоростях свыше 3 кбит/с при работе с каналом многостанционного доступа спутника-ретранслятора.

Поэтому предлагается компромиссное трехступенчатое построение трехканальной АAР:

- в первом радиоканале ААР работает на одну антенну и передает в расчете на широкий луч спутника-ретранслятора в реальном масштабе времени со скоростью 700 бит/с минимально необходимое количество измерительной информации для встречи КА-абонента на территории России: вектор состояния на момент окончания динамической операции $\mathrm{PH} / \mathrm{PБ} / \mathrm{KA}$ и обобщенную информацию о состоянии систем $\mathrm{PH} / \mathrm{PБ} / \mathrm{KA}$ типа «нормане норма»;

- во втором радиоканале ААР работает на вторую антенну и передает в реальном масштабе времени со скоростью 64 кбит/с репортажную телеметрическую информацию, если спутникуретранслятору удалось узким лучом «захватить» КА-абонент;

- в третьем радиоканале ААР работает на АФАР и передает в реальном масштабе времени полный поток телеметрической информации с максимально предусмотренной скоростью, если с использованием данных системы управления о местоположении КА-ретранслятора, ОРКТ-абонента 
и ориентации ОРКТ-абонента системе наведения АФАР ОРКТ-абонента удастся «поймать» КА-ретранслятор.

В соответствии с данными таблицы компромиссное трехступенчатое трехканальное построение ААР потребует суммарной излучаемой мощности радиосигналов 60 Вт и позволит в худшем случае гарантированно получить минимально необходимый объем измерительной информации для «встречи» ОРКТ-абонента на территории России с последующим получением телеметрии в записи, а в лучшем случае получить полный поток телеметрии о состоянии и местоположении KA-абонента в реальном масштабе времени. Такая реализация ААР удачно дополняет НАКУ и существенно повышает надежность информационнотелеметрического обеспечения выведения и управления KA.

\section{Вывод}

Применение трехступенчатой трехканальной абонентской аппаратуры ретрансляции наряду с АФАР надежно решает проблему передачи телеметрической информации с объекта ракетнокосмической техники через спутник-ретранслятор и является удачным дополнением НАКУ КА и измерений.

\section{Список литературы}

1. Гриимановский B.A., Степанов B.C. Расчет дальности, времени видимости KA и энергетических характеристик радиолиний для передачи телеметрической информации. Учебно-методическое пособие к практическим занятиям по курсу «Командно-измерительный комплекс управления». ВИКИ им. А. Ф. Можайского. 1985 г.

2. Энергетические характеристики космических радиолиний / Под ред. О. А. Зенкевича. М.: Сов. радио, 1972.

3. ОАО «НИИ КП». Создание абонентской аппаратуры ретрансляции многофункциональной космической системы ретрансляции «Луч». Пояснительная записка. Основные проектные решения и технические характеристики. Книга 1. 2013 г.

4. Министерство образования и науки Российской федерации. Национальный исследовательский университет «МЭИ». Материалы эскизного проекта по составной части опытно-конструкторской работы «Исследование и расчеты радиолиний абонентской аппаратуры ретрансляции многофункциональной системы “Луч”». Москва, 2013 г. 